\title{
INSTITUIÇÃO JURÍDICA DA LIBERDADE DE CONSCIÊNCIA E DE RELIGIÃO. ANÁLISE COMPARATIVA: O ESTADO ATUAL NA RÚSSIA, NA UNIÃO EUROPEIA, ITÁLIA E ESPANHA
}

\author{
LEGAL DOCRTINES OF FREEDOM OF CONSCIENCE AND RELIGION: COMPARATIVE ANALYSIS \\ OF THE CURRENT STATE IN RUSSIA, EUROPEAN UNION, ITALY AND SPAIN
}

Ekaterina Lagoda*

\begin{abstract}
Resumo:
No artigo serão examinadas as direções principais de desenvolvimento da instituição da liberdade de consciência e de religião na etapa atual na Federação Russa, no contexto do direito da União Europeia e do direito de certos países europeus - Itália e Espanha. Na base da análise comparativa se revelam as tendências globais e as características distintivas da regulamentação constitucional as quais predeterminam a forma e conteúdo da constituição jurídica da liberdade de consciência e de religião nos países pesquisados, considerando a influência do Direito Internacional nesta área.

Palavras-chave: Liberdade de consciência. Liberdade de religião. Instituição jurídica. Constituição, Rússia. União Europeia. Itália. Espanha. a legislação atual, os standards internacionais.
\end{abstract}

\begin{abstract}
:
This paper examines the development of main aspects of the doctrine of freedom of conscience and religion at the present stage in the Russian Federation, in the context of European Union law and law of certain European countries - Italy and Spain. On the basis of comparative analysis, it was highlighted global trends and particular features of the constitutional regulation which predetermine the form and content of the doctrine of freedom of conscience and religion in the studied countries, taking into account the influence of international law-making in this area.
\end{abstract}

Keywords: Freedom of conscience. Freedom of religion Doctrine. Constitution. Russia. European Union. Italy. Spain. Actual legislation, international standards.

O direito da escolha da visão de mundo, os elementos constitutivos do que é a liberdade de consciência e de religião, têm um lugar especial no sistema da regulação constitucional-jurídica. A análise das constituições vigentes dos estados modernos permitedizer que, independentemente do tempo e do contexto político-social da sua aprovação, a maior parte deles tem normas sobre a liberdade de consciência e de religião.

\footnotetext{
* Pesquisadora do Departamento de Direito Estatal e Internacional da Universidade KubGAU (Rússia, Krasnodar).

Responsável do Consulado Geral Honorário da Itália em Krasnodar. indiya-ray@yandex.ru.
} 
As particularidades legal, confessional e cultural de diferentes estados determinam a especificidade da segurança constitucional deste direito. Qualquer discriminação, violação de interesses e perseguições como motivos de pertinência religiosa ou seguir qualquer crença é avaliada de acordo com a compreensão da legislação atual, sendo mais ampla do que o método de coerção do Estado contra uma pessoa ou grupo de pessoas, porém è considerada como ação não só contra democracia, mas também contra uma grave violação dos fundamentos constitucionais do Estado.

Até a hoje, uma das principais tendências do desenvolvimento da instituição jurídica estudada è uma deslocação do acento na componente internacional na realização do conceito de direitos e liberdades humanos no âmbito da consciência e de religião, ligado com a elaboração das normas internacionais e decisões judiciários em questão.

Outra tendência se refere ao processo mundial de globalização e, como consequência, com a propagação de doutrinas religiosas, filosóficas e ideológicas, acompanhadas por fenômenos tão contraditórios como o crescimento da importância das religiões mundiais no fundo da secularização geral da vida de seus seguidores e o surgimento de sistemas religiosos e filosóficos, os quais em um curto período foram capazes de competir com as crenças religiosas existentes através dos séculos pelo número de seguidores e geografia de difusão etc.

Deve-se notar que as diferenças conceituais de noção e conteúdo da liberdade de consciência e de religião são correspondentes à série de novas realidades, aos mecanismos e meios de realização jurídica para o quais estão em estágio de formação. Assim, as questões da aplicação das regras religiosas, para resolver as questões jurídicas, as controvérsias decorrentes da formalização de documentos em conformidade com os requisitos que não estão em conformidade com as exigências da consciência o de religião (questões de atribuição de números de identificação, o uso de tecnologia da biometria nos documentos, fotografia nos documentos com os atributos de pertinência religiosa) aplicação das biotecnologias, etc., se obriga a direcionar-se novamente ao conteúdo desta instituição jurídica, criando uma base teórica e os mecanismos legislativos regulatórios que correspondem às realidades sociais modernas

A Federação Russa passou por diversas etapas de formação da liberdade de consciência e de religião. Inseridos na Constituição vigente da Federação Russa de 1993, ${ }^{1}$ os princípios da liberdade de consciência e não-discriminação em relação à religião criam as condições necessárias para a existência de um país multiétnico e multi-religioso. No entanto, a realização prática do complexo destes direitos e liberdades provoca uma série de complexidades e contradições. A transformação da instituição jurídica estudada predomina atualmente.

Konstituciya Rossiiskoi Federacii 1993 goda. M., 2012. P.4. 
Primeiramente, damos a característica do estado atual da legislação da Federação da Rússia no âmbito da liberdade de consciência e de religião. Em geral, a hierarquia das fontes forma: ${ }^{2}$

1) Os princípios e as normas do Direito Internacional geralmente reconhecidos e os tratados internacionais da Federação Russa;

2) A Constituição da Federação Russa de 1993;

3) Lei Federal "De liberdade de consciência e associações religiosas" de 1997;

4) Os Códigos da Federação Russa: Civil, Administrativo, Tributário, Penal, Trabalhista e assim por diante;

5) Os atos federais do nível secundário adotados para garantir a aplicação de artigos específicos e as disposições da Lei Federal "De liberdade de consciência e associações religiosas" de 1997;

6) Outras normas federais que tratam das questões de liberdade de consciência, liberdade de religião e de atividade das associações religiosas;

7) Os atos normativos legais do Sujeitos da Federação.

Uma parte importante na regulação das relações entre Estado e organisaçoes religiosas também desempenhou as decisões do Tribunal Constitucional da Federação da Rússia. ${ }^{3}$

Decisões do Tribunal Europeu dos Direitos Humanos ligadas à violação do direito de liberdade do pensamento, consciência e religião feitas contra à Rússia podem ser consideradas como a mais recente fonte do instituto jurídico.

A vigente Constituição da Federação Russa de 1993 inclui as normas de partida, as quais formam os princípios básicos como a laicidade do Estado (art. 14), a separação de associações religiosas do estado e sua igualdade perante a lei (art. 14); igualdade de direitos humanos e civis, independentemente de religião (art. 19), a proibição da propaganda, que provoca ódio e inimizade religiosa, bem como a promoção de superioridade religiosa (art. 29), o direito ao serviço alternativo militar (art. 59) dentre outros.

No art. 28, o qual revela o significado principal do direito examinado, afirma-se que: “A todos é garantida a liberdade de consciência e de religião, incluindo o direito de professar, individualmente ou em conjunto com os outros de qualquer religião ou professar nenhuma, de escolher livremente, possuir e divulgar as convicções religiosas e di outro tipo e agir acordo com eles."

2 BASHIROV L.A., KUDRINA T. A., LOPATKIN R. A., PINKEVICH V. K., TROFIMCHUK N. A. Religiya, svoboda sovesti, gosudarstvenno-cerkovnye otnosheniya v Rossii: Spravochnik. M., RAGS, 2011. p. 45.

3 VOLODINA, N. Konstitucionno-pravovye osnovy gosudarstvenno-cerkovnyh otnoshenii v Rossii: XX vek. Moscou, 2010. p. 54. 
Estes princípios básicos têm ulterior desenvolvimento na Lei Federal de 26.09.1997 n. 125-FZ "Sobre liberdade de consciência e associações religiosas"4 com as alterações e aditamentos posteriores.

A Lei regula as relações legais em âmbito da liberdade de consciência e de religião e estado jurídico das associações religiosas. É constituída por um preâmbulo e 27 artigos, divididos em quatro capítulos:

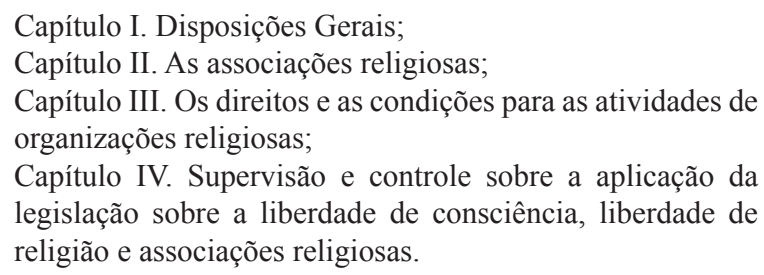

O primeiro capítulo da Lei, que é composto por cinco artigos, disposições gerais, objeto e sujeito, regulados pela lei, determina as fontes de legislação sobre a liberdade de consciência, revela o conceito de liberdade de consciência e de religião, de educação religiosa e regula as relações jurídicas decorrentes entre as autoridades e organizações religiosas.

Os elementos estruturais do instituto se revelam através do reconhecimento de oportunidade a fim de praticar individualmente ou em conjunto com os outros de qualquer religião ou com aqueles que não profetizam nenhuma religião, escolher livremente, mudar, manter, disseminar as crenças religiosas e outros pensamentos e agir de acordo com eles.

Art. 3 ponto 4 prevê oportunidade caso as convicções ou a crença religiosa contradizerem o serviço militar, tendo o direito de substituir com o serviço civil alternativo.

Art. 3 ponto 7 prevê que o segredo de confissão é protegido por lei. $\mathrm{O}$ sacerdote não pode se responsabilizar ao se recusar a testemunhar as circunstâncias que eram conhecidas por ele durante a confissão. É importante que esta norma se aplique igualmente aos representantes de todas as confissões, garantindo assim a sua igualdade perante a lei.

Capítulo II. "As associações religiosas" contêm disposições que estabelecem a ordem da criação e registro de organizações religiosas. Neste capítulo, revela-se o aspecto civil das atividades de organizações religiosas.

Capítulo III. "Os direitos e condições para as atividades de organizações religiosas" revelam o conteúdo de alguns aspectos das atividades de organizações religiosas, como os ritos e cerimônias religiosas, caridade, atividades culturais e educacionais e outras atividades que acompanham a implementação dos objetivos estatutários.

$4 \quad$ Lei Federal de 26.09.1997 n. 125-FZ “Sobre liberdade de consciência e associações religiosas», Moscou, 2012. 
Capítulo IV. "Supervisão e controle sobre a aplicação da legislação sobre a liberdade de consciência, a liberdade de religião e de associações religiosas" prevê que a violação da legislação russa sobre a liberdade de consciência, a liberdade de religião e de associações religiosas implica responsabilidade penal, administrativa ou outra, de acordo com as leis da Federação Russa.

A supervisão de implementação da legislação russa realiza as autoridades de promotoria da Federação Russa.

Nota-se que a lei examinada está sistematicamente sujeita a mudanças que são projetadas para preencher as lacunas e alinhá-las com a realidade.

Em seguida, destacamos os mais importantes atos legislativos pelos quais se pode analisar o desenvolvimento e estado atual da instituição legal da liberdade de consciência e de religião como o direito pessoal constitucional. Entre as Leis Federais indicamos:

- A Lei Federal de 11 agosto 1995 n. 135-FZ "Sobre atividades de caridade e organizações de caridade";

- $\quad$ A Lei Federal de 30.11.2010 n. 327-FZ "Sobre a transferência para as organizações religiosas de propriedade para fins religiosos que è de propriedade estadual ou municipal";

- A Lei Federal de 25 de julho 2002 n. 113-FZ "Do Serviço Civil Alternativo";

- A Lei Federal de 19 junho 2004 n. 54-FZ "Do Assembléias, comícios, manifestações, desfiles e piquetes";

- A Lei Federal de 25 de julho 2002 n. 114-FZ "Da luta contra a atividade extremista";

- A Lei Federa 07.10.1992 n. 3266-1 "Sobre a Educação";

- A Lei Federal de 03.06.2006 n. 35-FZ "Da luta contra o terrorismo";

Em síntese, através da análise da instituição jurídica da liberdade de consciência e de religião, pode-se dizer que, hoje, na Rússia, há um sistema multinívelado, que incorporou os elementos previstos do Direito Internacional, as normas de regulamentação constitucional e uma lei específica federal. Todos os códigos principais da FR contêm regras especiais necessárias para a regulamentação e autorização de certos aspectos da realização do direito examinado.

Transformação das normas legislativas relativas ao direito à liberdade de consciência e de religião passa por um período intensivo. Para o ano de 2012 as principais tendências no âmbito da liberdade de consciência e de religião podem ser consideradas controversas. Durante vários anos, a comunidade científica, incluindo representantes de comunidades religiosas e das autoridades políticas, tem polêmica sobre questões relacionadas com a implementação da instituição jurídica examinada. 
A partir da consideração do estado atual do direito de liberdade de consciência e de religião na Federação Russa, vamos analisar a instituição análoga ao direito da União Europeia. Este estudo é interessante sob várias posições. Primeiramente, a Europa moderna é um exemplo de coexistência de sistemas de pensamento diametralmente opostos - religiosos e seculares. Além disso, os processos da migração dentro da União, bem como o afluxo de imigrantes submetem à prova o sistema de reconhecimento e proteção dos direitos no âmbito religioso e de consciência.

No entanto, o mais importante é o fato de que se pode falar de um "modelo da União Europeia da instituição jurídica da liberdade de consciência e de religião", elaborado no nível da União. Além do fato de que este modelo é, no momento atual, vale para os 27 países-membros da União, faz a influência fora dos confins da UE. Como resultado dos processos de unificação na UE, afirmar-se cada vez mais o problema de correlação entre as políticas nacionais dos países-membros em matéria de liberdade religiosa. ${ }^{5}$

Examinamos as principais etapas da integração européia, que são conectados com a formação e desenvolvimento da instituição legal estudada, bem como a parte e o lugar da religião e da igreja nos processos de integração da UE.

Um dos primeiros passos foi a adoção em 1950 da Convenção Européia dos Direitos do Homem e das Liberdades Fundamentais. Em plena conformidade com os princípios estabelecidos na Convenção era o documento legal aplicável, sendo apoiada com o mecanismo para garantir os direitos e as liberdades estabelecidas - a Comissão Europeia dos Direitos Humanos (em vigor a partir de 1955 até 1999), depois convertida para o Tribunal Europeu dos Direitos Humanos. ${ }^{6}$

Para a proteção da liberdade de consciência è dedicado o art. 9 da Convenção. A primeira parte dela repete palavra por palavra o conteúdo do art. 18 da Declaração Universal dos Direitos Humanos, mas já como uma norma vinculativa.

Na segunda parte, prevê-se que a liberdade de professar religião ou as próprias crenças estará sujeita apenas às limitações, que em primeiro lugar, são estabelecidas pela lei e, por outro, são necessárias numa sociedade democrática, no interesse da segurança pública, defesa da ordem pública, da saúde e da moralidade ou para defesa dos direitos e liberdades de outras pessoas. Assim, o rol de interesses protegidos, o que pode servir de base para restringir a liberdade de consciência, é fechado - devido a sua formulação, ele não pode ser arbitrariamente estendido.

\footnotetext{
5 MARGIOTTA BROGLIO F., BOLGIAN F., MAZZOLA R. Chiese cristiane, pluralismo religioso e democrazia liberale in Europa. Bologna: Il Mulino, 2006. p. 124.

6 Disponível em:

$<$ http://www.echr.coe.int/ECHR/EN/Header/The+Court/Introduction/ Information+documents/>.
} 
Como se pode notar, na Convenção são baseadas duas direções principais de regulamentação europeia em matéria de liberdade de consciência e de religião. A primeira direção é a seguinte: a proteção da liberdade de consciência como direito de qualquer pessoa de praticar livremente uma religião, que inclui aspectos como a liberdade de mudar de religião ou crença; a garantia à liberdade de professar uma religião, como por exemplo, a liberdade de praticar suas crenças em público ou privado, individualmente ou com os outros, através das formas usuais para isso.

A segunda direção principal da regulamentação é assegurar a tolerância e a coesão social a fim de que realização da liberdade de consciência de algumas pessoas não limita os direitos e liberdades de outrem. É por isso que a Convenção estabelece as regras relativas à possível restrição da liberdade de consciência.

No nível legislativo, a fórmula jurídica do direito europeu é a "liberdade de pensamento, consciência e religião". O desenvolvimento do direito europeu se dirigiu no caminho para constituir a UE como uma instituição secular, garantindo assim a liberdade de consciência não somente para os praticantes de todas as religiões, assim como ateus. Atualmente, a separação entre Igreja e Estado se fixa nas constituições da maioria dos países da União. ${ }^{7}$

Vamos examinar a instituição jurídica análoga, citando dois distintos países europeus. República Italiana e o Reino da Espanha são exemplos de países que, por um lado, são envolvidos no processo legal de integração européia, por outro lado, continuam a constituir-se independente da legislação nacional sobre liberdade de consciência e de religião.

Análise do estado atual da instituição legal examinada mostra que, para esses países, resta ainda discutir a série de questões que afetam diversos aspectos do direito à liberdade de consciência.

Após a assinatura da Itália, junto com outros estados, uma série de acordos internacionais de caráter universal, que sugerem o secularismo como um dos padrões internacionais, no nível de direito nacional, não seguiu a inserção das alterações correspondentes do caráter secular do Estado na Constituição de 1948. Também não há uma única lei sobre a liberdade de consciência e de religião. ${ }^{8}$

No estágio atual, a instituição jurídica da liberdade de consciência e de religião na Itália é regulada por um sistema de atos normativos, como base nos quais inclui a Constituição da República da Itália do1948, ${ }^{9}$ o Acordo entre a República da Itália

MARGIOTTA BROGLIO F. La protezione internazionale della libertà religiosa nella Convenzione europea dei diritti dell'uomo. Milano, 2008. p. 70.

8 NESTI, A. Qual'e la religione degli italiani? Religioni civili, mondo cattolico, ateismo devoto, fede, laicità. Firenze: Firenze University Press, 2006. p. 37.

$9 \quad$ La Costituzione della Repubblica Italiana 1948, Roma, 2011. p. 21. 
e a Santa Sé dos 18 fevereiro de $1984^{10}$ com as alterações. Além destes, existem várias leis que regulam as relações entre Itália e denominações religiosas distintas. Oferecemos uma análise destes atos normativos que devem ser considerados como fontes dessa instituição.

Assim, o art. 7 da Constituição regula as relações entre a Itália e a Igreja Católica e estabelece que: “O Estado e a Igreja Católica são independentes e soberanos; cada uma deles na área pertencente. Suas relações são reguladas por Acordos de Latrão. Alterações destes acordos por ambas as partes não requerem qualquer processo de revisão da Constituição."

Art. 8 da Constituição prevê o princípio de igualdade para todas as religiões, que tenham sido atribuídas da seguinte forma: "Todas as confissões religiosas são igualmente livres perante a lei. As confissões religiosas que não sejam católicos têm o direito de se organizar de acordo com seus estatutos, enquanto não entrem em conflito com o ordenamento jurídico italiano. Sua relação com o estado definido pela lei com base em acordos com organizações que representam as religiões."

Art. 19 estabelece uma asseguração direta do conteúdo da liberdade de consciência e de religião: "Todos têm o direito de praticar suas crenças religiosas sob qualquer forma, individualmente e coletivamente, de promovê-las e seguir os cultos em privado ou em público, exceto para os ritos, contrários aos bons costumes.”.

$\mathrm{O}$ art. 20 estabelece garantias econômicas da realização do direito a liberdade religiosa: “O caráter religioso e os fins religiosos ou rituais das instituições não podem ser uma razão para as restrições especiais legislativas ou medidas especiais fiscais entre a sua fundação, seu estatuto legal e qualquer forma de atividade.”.

$\mathrm{O}$ art.117 ponto c) entre as áreas em que o Estado tem o direito exclusivo de iniciativa legislativa, destaca: "a relação entre República e as fés religiosas.”.

De particular importância entre as fontes dessa instituição, há o Acordo entre a República Italiana e a Santa Sé de 1984, sendo o resultado de longas negociações entre a Itália e o Vaticano sobre a questão da revisão dos acordos de Latrão, assinados em 1929, considerando que o Catolicismo é a religião oficial da Itália.

Em seguida, segue a particularidade inerente exatamente no modelo italiano; o sistema de atos normativos que estabelecem legalmente certos aspectos da implementação da liberdade de consciência e de religião. ${ }^{11}$

As garantias legais e proteção penal dos sentimentos religiosos dos cidadãos são incluídas no Código Penal italiano com base dos artigos 402, 403, 404, 405, 406 e 724 do Código Penal da Itália. ${ }^{12}$

10 L'Accordo tra la Repubblica Italiana e la Santa Sede del 18 febbraio 1984. http://www.governo.it/Presidenza/USRI/confessioni/accordo_indice. html\#1.

11 FERRARI, S. La nozione di laicita tra identita e pluralismo. In: CERETTI, A.; GARLATI, L. Laicita e Stato di diritto. Milano: Ed. Giuffre, 2007. p. 44.

12 Quattro codici. Civile e di procedura civile, penale e di procedura penale (Tribuna pocket), Roma, 2011. p. 
Uma das características da instituição legal da liberdade de consciência e de religião na Itália é o mecanismo de reconhecimento das confissões religiosas distintas das confissões católicas. Estabelecido no art. 8 da Constituição, o direito a outras religiões de realizarem suas atividades para cada uma delas começa nos procedimentos obrigatórios da conclusão do acordo entre o Governo italiano e Confissão; tal prática adotada também em outros países de tradição católica, por exemplo, em Espanha. Mas, a diferença crucial é que, na Itália, o acordo è feito não com uma "grande família", que é composta de todas as denominações e credos da mesma confissão, mas também especificamente com cada organização. Isso complica e obstrui a legislação nesta área, tornando-o casuístico.

A tendência principal na instituição legal da liberdade de consciência e de religião é que, reconhecendo a laicidade da República Italiana, a situação prática sugere o falar da estreita conexão dos italianos com a Igreja Católica italiana. ${ }^{13}$ Há, também, uma situação típica de outros estados, quando o relacionamento com a denominação de liderança, neste caso, o catolicismo romano, na consciência cotidiana é entendida não só como uma petinência religiosa, mas como um estatuto sócio-cultural geral do indivíduo, parte da sua identidade nacional.

Reino de Espanha tem a história da formação e consolidação da instituição legal da liberdade de consciência e de religião característica dos países católicos da Europa. A singularidade da situação em relação à igreja e religião se desenvolveu na Espanha, em relação com o fato de que a relação tradicionalmente profunda da igreja e do estado permaneceu aqui até o século XX. Todas Constituições espanholas - dos 1812, 1837, 1869 e 1876, incluindo a constituição da Primeira República Espanhola declarou o catolicismo a religião oficial. ${ }^{14}$

Após a assinatura da Espanha, juntamente com outros estados, uma série de instrumentos internacionais de caráter universal a nível legislativo foi proclamada, adotando os princípios de prioridade de direitos humanos, o princípio da laicidade e da igualdade das religiões perante a lei. Assim, a Espanha é geralmente caracterizada como um estado secular no qual não há religião oficial do Estado.

No estágio atual, a instituição legal da liberdade de consciência e de religião no estado é governada pelo seguinte sistema dos atos normativos. Atos normativos de base nesta área incluem a Constituição espanhola de $1978^{15}$ e Lei 7/1980 "Sobre a Liberdade

30 .

13 CASUSCELLI, G. Diritto ecclesiastico ed attuazione costituzionale tra de-formazione e proliferazione delle fonti. Milano, 2010. p. 10.

14 IBAN, I.C. El contenido de la libertad religiosa. Anuario de Derecho Eclesiástico del Estado, Madrid, v. 1, 2007. p. 74.

15 La Constitución Española de 1978, VV.AA., Madrid, 2011, p. 9. 
Religiosa". ${ }^{16}$ Além deles, existem algumas leis orgânicas que contêm certas regras da esta instituição. Oferecemos uma análise de leis supracitadas.

Assim, o art. 16 da Constituição estabelece uma direta fixação do conteúdo da liberdade de consciência e de religião: "1. Garantida a liberdade ideológica, religiosa e liberdade de culto, realizada por indivíduos e suas associações, sem quaisquer restrições, exceto aquelas que são necessárias para a manutenção da ordem pública protegida por lei. 2. Ninguém pode ser obrigado a declarar a sua ideologia, religião e crenças. 3. Nenhuma denominação não pode ter o caráter de uma religião de Estado. As autoridades públicas devem levar em conta as crenças religiosas da sociedade espanhola e manter as relações conseqüentes de cooperação com a Igreja Católica e outras religiões."

Art. 14 da Constituição estabelece princípios importantes de direitos humanos e liberdades dos cidadãos da Espanha, que são fixados na seguinte forma: "Todos os espanhóis são iguais perante a lei, e esta proíbe qualquer discriminação baseada em raça, nascimento, sexo, religião, opinião ou sobre outros fundamentos pessoais ou sociais. "No art. 27, ponto 3 são prescritos as garantias do isso instituto: "As autoridades públicas garantiram o direito dos pais de escolher para seus filhos educação moral e religiosa de acordo com suas próprias convicções."

A Lei 7/1980 de 05 de julho "Sobre a liberdade religiosa" inclui doze artigos, dos quais oito são artigos principais; dois artigos das disposições transitórias; um art. sobre a abolição da lei e um art. final. A fórmula legal da lei é um "direito fundamental à liberdade religiosa e liberdade de culto", proclamado pela Constituição de 1978. Além disso, a lei prevê a impossibilidade de discriminação baseada na religião, e na ausência de uma religião de Estado.

Assim, a instituição jurídica é entendida tanto em termos de direito pessoal, bem como o direito de organizações religiosas. ${ }^{17}$ As limitações do presente direito são previstas só em caso de ameaça à segurança, saúde e moralidade pública, bem como no caso de invasão sobre os fundamentos constitucionais da ordem pública em condições de uma sociedade democrática.

Dentre outras Leis Orgânicas Fundamentais (espanhol Leyes Orgánicas Fundamentales) do Ministério da Justiça da Espanha são nominadas: A lei que rege o direito de associação. 1/2002 22 de marco (Ley Orgánica del Derecho reguladora de Associação, LO 1/2002 de 22 de março). Lei "Sobre Prisões" de 26 setembro de 1979 (Lei Orgânica Geral Penitenciaria, LO 1/1979 de 26 de setembro ). A lei "Sobre a Educação" 200603 de maio (Ley Orgánica de Educación, LO 2/2006 de 3 de mayo). Lei "Sobre as Universidades» 200712 de Abril (Lei Orgânica de Universidades, LO 4/2007 de 12 de

16 La Ley Orgánica 7/1980 “De Libertad religiosa”, VV.AA., Madrid, 2010, P. 5.

17 TORRES GUTIÉRREZ ALEJANDRO. El derecho fundamental de libertad religiosa en España: un balance crítico. Boletín de la Comunidad Foral, Navarra, n. 36, 2003. p. 40. 
abril). Lei "Sobre os direitos e liberdades dos estrangeiros na Espanha", de 22dezembro de 2000 (Lei Orgânica de derechos y libertades de los Extranjeros en España, LO 8/2000 de 22 de diciembre).

Defesa penal da liberdade religiosa é baseada no Código Penal n. 10/1995 de 23 Novembro na parte "Os crimes contra a liberdade de consciência, de sentimentos religiosos e respeito pelos mortos" nos art. 522, 523, 524, 525, 526 (Código Penal de los delitos contra la libertad de conciencia, los sentimientos religiosos y el respeto a los difuntos, L.O. 10/1995 de 23 de noviembre).

Existe uma característica importante do instituto legal de liberdade de consciência e de religião na Espanha, sendo que um grupo especial de regulamentação jurídica nesta área constitui os Acordos concluídos entre o Governo Espanhol com denominações religiosas. Todos os acordos são divididos em dois grupos: com a Igreja Católica e os Acordos com outras religiões. ${ }^{18}$

$\mathrm{Na}$ sociedade moderna espanhola, há debates comuns também em outros estados sobre a necessidade de reformar a legislação na esfera da religião e de arranjar-le atualizando a base normativa, com os padrões internacionais. Outro ponto polêmico é o ensino da religião nas escolas públicas, bem como um fato bem conhecido do caráter de crucifixos católicos nas salas de aula e locais públicos. ${ }^{19}$

Examinando a literatura científica espanhola sobre o tema da liberdade de consciência e de religião, valorizando os relatórios e informações de massa em mídia, no nosso ponto de vista, pode-se dizer que na sociedade espanhola moderna, ao mesmo tempo, há duas tendências contrastantes no exercício da liberdade de consciência e de religião. Assim, a primeira tendência é a discussão científica da noção de "liberdade de consciência" e "liberdade de religião", a busca de variantes de realização do direito de determinados grupos religiosos, que manifestam dos seus direitos, apoiando-se sobre as normas no Direito Internacional, bem como sobre os “padrões" estabelecidos em quadro da integração européia. ${ }^{20}$

A segunda tendência, segundo o autor, é um forte entrelaçamento entre a vida cotidiana com as normas religiosas, o que, para a maioria da população é percebida como um componente do status sócio-cultural dos cidadãos espanhóis, como um atributo de sua origem nacional.

18 http://www.mjusticia.gob.es/cs/Satellite/es/1215197983369/Estructura_P/1215198058699/Detalle. html.

19 CASTRO JOVER, A. La libertad de conciencia y la objeción de conciencia individual en la jurisprudencia constitucional Española. In: MARTINEZ-TORRON, J. La libertad religiosa y de conciencia ante la justicia constitucional. Actas del VIII Congreso Internacional de Derecho Eclesiástico del Estado, Granada, 1998. p. 167.

20 SOUTO PAZ, J. A. Relevancia jurídica de las minorías religiosas. Derechos de las minorías en una sociedad multicultural. Madrid: Consejo General del Poder Judicial. 2009. p. 137. 
Resumindo o exame da transformação da instituição jurídica da liberdade de consciência e de religião, pode-se concluir que a tendência principal do estado atual da esta instituição é a aproximação das bases conceituais do conceito e conteúdo da instituição em diferentes países sob a influência do Direito Internacional.

Os acontecimentos das últimas décadas, ligados às violações da liberdade de consciência e de religião ao redor do mundo sugerem que um modelo equilibrado da instituição legal da liberdade de consciência e de religião não se encontra definitivamente. Um estudo mais aprofundado da experiência nacional e internacional da implementação da instituição legal da liberdade de consciência e de religião irá facilitar a busca de ótimos mecanismos de regulamentação legal de certos aspectos da realização do direito à autodeterminação religiosa e moral das pessoas.

Krasnodar, Rússia, maio de 2012.

\section{Referências}

BASHIROV, L. A.; KUDRINA T. A., LOPATKIN, R. A.; PINKEVICH, V. K.; TROFIMCHUK N.A. Religiya, svoboda sovesti, gosudarstvenno-cerkovnye otnosheniya v. Rossii: Spravochnik. M., RAGS, 2011.

CASTRO JOVER, A. La libertad de conciencia y la objeción de conciencia individual en la jurisprudencia constitucional Española. In: MARTINEZ-TORRON, J. La libertad religiosa y de conciencia ante la justicia constitucional. Actas del VIII Congreso Internacional de Derecho Eclesiástico del Estado. Granada, 1998.

CASUSCELLI, G. Diritto ecclesiastico ed attuazione costituzionale tra de-formazione e proliferazione delle fonti. Milano, 2010.

FERRARI, S. La nozione di laicita tra identita e pluralismo. In: CERETTI, A.; GARLATI, L. Laicita e Stato di diritto. Milano: Ed. Giuffre, 2007.

http://www.echr.coe.int/ECHR/EN/Header/The+Court/Introduction/Information+documents/

http://www.governo.it/Presidenza/USRI/confessioni/accordo_indice. html\#1

http:/www.mjusticia.gob.es/cs/Satellite/es/1215197983369/Estructura_P/1215198058699/Detalle. html.

IBAN, I.C. El contenido de la libertad religiosa. Anuario de Derecho Eclesiástico del Estado, Madrid, v. I, 2007.

KONSTITUCIYA Rossiiskoi Federacii 1993 goda. M., 2012.

L'ACCORDO tra la Repubblica Italiana e la Santa Sede del 18 febbraio 1984.

LA CONSTITUCIÓN Española de 1978, VV.AA., Madrid, 2011.

LA COSTITUZIONE della Repubblica Italiana ,1948. Roma, 2011. 
LA LEY Orgánica 7/1980 “De Libertad religiosa”, VV.AA., Madrid, 2010.

LEI Federal de 26.09.1997 n. 125-FZ "Sobre liberdade de consciência e associações religiosas", Moscou, 2012.

MARGIOTTA BROGLIO F. La protezione internazionale della libertà religiosa nella Convenzione europea dei diritti dell'uomo. Milano, 2008.

MARGIOTTA BROGLIO, F.; BOLGIAN, F.; MAZZOLA, R. Chiese cristiane, pluralismo religioso e democrazia liberale in Europa. Bologna: Il Mulino, 2006.

NESTI, A. Qual'e la religione degli italiani? Religioni civili, mondo cattolico, ateismo devoto, fede, laicità. Firenze: Firenze University Press, 2006.

QUATTRO codici. Civile e di procedura civile, penale e di procedura penale (Tribuna pocket), Roma, 2011. p. 30.

SOUTO PAZ, J. A. Relevancia jurídica de las minorías religiosas. Derechos de las minorías en una sociedad multicultural. Madrid: Consejo General del Poder Judicial, 2009.

TORRES GUTIÉRREZ ALEJANDRO. El derecho fundamental de libertad religiosa en España: un balance crítico. Boletín de la Comunidad Foral, Navarra, n. 36, 2003.

VOLODINA, N. Konstitucionno-pravovye osnovy gosudarstvenno-cerkovnyh otnoshenii v Rossii: XX vek. Moscou, 2010, p. 54. 